\title{
Adequações ambientais à legislação florestal brasileira em três propriedades distintas no sul de Minas Gerais
}

\section{Environmental adjustments to the Brazilian forest legislation in three different properties in south of Minas Gerais}

\author{
Washington Passos Rezende ${ }^{1}$; Otavio Duarte Giunti ${ }^{2}$; Thiago Cardoso de Oliveira ${ }^{3}$; Ariana Vieira Silva ${ }^{4}$; \\ Marcelo Antonio Morais ${ }^{5}$
}

\begin{abstract}
Resumo: Este trabalho teve por objetivo analisar a situação de três propriedades distintas na região de Poço Fundo, sul de Minas Gerais, em relação à adequação das mesmas à legislação florestal. Para cada propriedade, foi feito um levantamento topográfico, com a construção da tabela de uso e ocupação atual do solo. Foi feita a adequação de cada propriedade à Lei ${ }^{\circ}$ 4.771 (antigo Código Florestal) e uma nova tabela de uso e ocupação foi construída com base nessa adequação. Também foi realizada a adequação de cada propriedade à Lei ${ }^{\circ} 12.651$ (novo Código Florestal), com a respectiva confecção da tabela de uso e ocupação do solo. De posse dessas tabelas, foi feita uma comparação, objetivando-se avaliar os impactos ambientais e econômicos da alteração legislacional, principalmente em relação às Áreas de Preservação Permanente (APP) e Reserva Legal (RL). Como resultados, o Novo Código Florestal (Lei $n^{\circ} 12.651 / 2012$ ), ao ser comparado com a Lei n 4771/1965, mostrou-se mais benéfico às três propriedades, do ponto de vista econômico, uma vez que a área destinada para a regularização das APP's e RL pela nova legislação ambiental mostrou-se inferior à exigida pela legislação anterior, o que pode resultar na continuidade da exploração agrícola em algumas áreas que anteriormente deveriam ser consideradas de preservação ou conservação, com utilização extremamente restrita. Em relação a aspectos ambientais, essas reduções de áreas podem impactar em diminuição da biodiversidade, qualidade e quantidade de recursos hídricos, que pode comprometer a sustentabilidade da produção agrícola.
\end{abstract}

Palavras-chave: Área de Preservação Permanente; Reserva Legal; Sustentabilidade; Recursos naturais.

Abstract: This study aimed to analyze the situation of three distinct properties in the region of Poço Fundo, south of Minas Gerais, in relation to the adequacy of the same forest legislation. For each property, a survey was made, with the construction of the table of current soil use and occupation. The suitability of each property to federal law $n^{\circ} 4.771$ (previous Forest Code) and a and a new table of current soil use and occupation was built based on this adaptation. It was also carried out the suitability of each property to federal law $n^{\circ} 12.651$ (New Forest Code), with the respective preparation of the table of current soil use and occupation. With these tables, a comparison was made, aiming to assess the environmental and economic impacts of legislacional change, especially in relation to the Permanent Preservation Areas (PPA) and Legal Reserve (LR). As a result, the New Forest Code (federal law $n^{\circ} 12.651$ / 2012), to be compared to federal law $n^{\circ} .4 .771 / 1965$ was more beneficial to the three properties, from an economic point of view, since the area for the regularization of PPAs and LR by new environmental legislation was lower than that required by the previous legislation, which may result in the continued operation agriculture in some areas that should be considered before the preservation or conservation, with extremely restricted use. In relation to environmental aspects, these reductions may impact areas in decrease of biodiversity, quality and quantity of water resources, which may compromise the sustainability of agricultural production.

Key words: Permanent Preservation Area; Legal Reserve; Sustainability; Natural resources.

\footnotetext{
*Autor para correspondência

Recebido para publicação em 04/03/2016; aprovado em 20/11/2016

${ }^{1}$ Técnico em Meio Ambiente, Instituto Federal de Educação, Ciência e Tecnologia do Sul de Minas Gerais - Campus Muzambinho. Muzambinho - MG. Email:wprezende@gmail.com

${ }^{2}$ Professor Msc., Instituto Federal de Educação, Ciência e Tecnologia do Sul de Minas Gerais - Campus Muzambinho. Muzambinho - MG. E-mail: otavio.ifsuldeminas@gmail.com

${ }^{3}$ Professor Msc., Instituto Federal de Educação, Ciência e Tecnologia do Sul de Minas Gerais - Campus Muzambinho. Muzambinho - MG. E-mail: thiago.oliveira@muz.ifsuldeminas.edu.br

${ }^{4}$ Professora Dra., Instituto Federal de Educação, Ciência e Tecnologia do Sul de Minas Gerais - Campus Muzambinho. Muzambinho - MG. E-mail: ariana.silva@muz.ifsuldeminas.edu.br

${ }^{2}$ Professor Msc, Instituto Federal de Educação, Ciência e Tecnologia do Sul de Minas Gerais - Campus Muzambinho. Muzambinho - MG. E-mail: marcelo.morais@muz.ifsuldeminas.edu.br
} 


\section{INTRODUÇÃO}

O processo continuado de retirada da cobertura vegetal, associado ao manejo incorreto do solo, tem promovido, ao longo dos anos, um aumento nos processos erosivos e, como consequência, gerando uma redução na fertilidade dos solos agrícolas, poluição e assoreamento de cursos d'água, culminando na redução da produção agrícola nessas áreas e a consequente necessidade de se buscar novos locais para a implementação de atividades agropecuárias (ATTANASIO et al., 2006). Ao mesmo tempo, essa fragmentação de habitats naturais afeta negativamente a biodiversidade, reduzindo a taxa de crescimento populacional, o comprimento e a diversidade da cadeia trófica, impactando nas interações entre as espécies e reduzindo a disponibilidade de serviços ecossistêmicos (ALBERTI, 2010; SEOANE et al., 2010).

Há uma visão de que a cobertura vegetal mostra-se como um empecilho ao desenvolvimento agrícola, repercutindo na redução de vários biomas brasileiros (RIBEIRO et al., 2009). Estima-se que mais de $60 \%$ dos 573 milhões de hectares de florestas brasileiras, em diferentes biomas, correspondam a áreas particulares, não inseridas dentro das áreas de proteção pública (ZAKIA; PINTO, 2013). Desse modo, Seoane (2007) indica que, muitas das áreas ocupadas por ecossistemas naturais mostram-se como pequenas manchas, denominadas fragmentos, cercados por áreas com intervenção humana. Assim, essa fragmentação mostra-se como uma das maiores ameaças à conservação da biodiversidade dos remanescentes das florestas tropicais.

Nesse sentido, há uma preocupação cada vez maior, por parte da sociedade civil e setor governamental, na criação, promulgação e aplicação de leis específicas de proteção ambiental, objetivando a redução dos impactos negativos da ação humana sobre o ambiente (OLIVEIRA et al., 2011).

Essa preocupação se refletiu na criação de várias leis e decretos almejando à proteção ambiental, cada um com suas limitações, eficiências e ineficiências. Em 1934, durante o governo de Getúlio Vargas, foi criado o $1^{\circ}$ Código Florestal, com a conceituação de florestas protetoras em propriedades agrícolas, objetivando a conservação das funções ecossistêmicas básicas, evidenciando a conservação de todo tipo de vegetação nativa (RIBEIRO, 2011; SANTOS FILHO et al., 2015).

Em 1965, após um processo de reformulação, foi sancionada a Lei Federal 4.771, instituindo outro Código Florestal, que determinou regras para a utilização, preservação e conservação das florestas e outras formas de vegetação em propriedades rurais, ou seja, as Áreas de Preservação Permanente (APP) e Reserva Legal (RL). Assim, esse código evidenciou a preservação não somente das florestas, mas também de diversos outros recursos e áreas ambientais estratégicas (RIBEIRO, 2011).

As áreas de preservação permanente, por estarem intimamente relacionadas às funções ambientais, promovem um ambiente ecologicamente equilibrado, mostrando-se como um bem de uso comum e essencial à vida, ao mesmo tempo em que, proporcionam a estabilização de ecossistemas às margens de corpos hídricos (BORGES et al., 2011). Já as áreas de Reserva Legal caracterizam-se por fragmentos de vegetação preservada dentro de uma propriedade rural, com objetivos de, mediante o manejo sustentável dos recursos naturais, auxiliar a conservação e a reabilitação dos processos ecológicos nessas propriedades (SANTOS FILHO et al., 2015).

Ao Código Florestal de 1965 foram feitas diversas alterações com o passar dos anos, alterando, entre várias questões, os regimes de proteção de APP's e RL's, demonstrando uma dificuldade dos legisladores em conciliar os interesses dos distintos grupos e entidades envolvidas na questão (CASTAGNARA et al., 2015). Desse modo, foi conferido um novo regime jurídico às áreas de Reserva Legal, através da ampliação do percentual de áreas mantidas com cobertura vegetal nas propriedades agrícolas e identificando um maior número de Áreas de Preservação Permanente (SPAROVEK et al., 2011)

Em 2008 foi editado o Decreto $\mathrm{n}^{\circ}$ 6.514, de 22 de julho de 2008, que discorre sobre as infrações e sanções administrativas ao meio ambiente, onde estabelece o processo administrativo federal para apuração destas infrações, e dá outras providências, regulamentando o Código Florestal. Ele detalha os procedimentos a serem adotados pelo Poder Público para dar cumprimento às medidas restritivas impostas pelo Código Florestal. Estabelece regras sobre a regeneração das Áreas de Preservação Permanente e de Reserva Legal e institui multas para quem impede ou dificulta essa regeneração (TAGLIALEGNA, 2011). Esse mesmo autor indica que, somente após a publicação desse decreto, ocorreu a real colocação do Código Florestal em prática, por instituir a multa como instrumento punitivo, viabilizando seu cumprimento.

Por pressões de diversos setores da sociedade, principalmente o agropecuário, houve um grande movimento para a discussão e revisão do Código Florestal. Após um período intenso e longo de discussões, de críticas e analises surgiu, então, a Lei $\mathrm{n}^{\circ}$ 12.651, de 25 de maio de 2012, denominada de novo Código Florestal, promovendo algumas alterações e considerando à produção agropecuária intimamente ligada ao meio ambiente, não podendo ser tratados separados, mas apresentando suas particularidades (GIUNTI et al., 2014; TAGLIALEGNA, 2011).

Assim, a nova legislação florestal indica mudanças expressivas quanto às normas de utilização do solo e dos recursos hídricos e promove a proteção dos recursos naturais bem como o desenvolvimento sustentável da população. Devido às proporções continentais do Brasil e a existência de regiões com características próprias, os impactos ambientais, sociais e econômicos resultante da aplicação da nova legislação pode ter consequências diferentes de acordo com as características locais de cada região.

O município de Poço Fundo e cidades no entorno se destacam por apresentarem um dos maiores parcelamentos de área agricultável do Estado de Minas Gerais. São, em geral, pequenas propriedades, geridas pela agricultura familiar, que utilizam quase sempre a totalidade de suas áreas para pratica da agricultura e pecuária leiteira, tendo assim um relevante passivo ambiental a ser recomposto.

Diante destas características e da obrigatoriedade de adequação a nova legislação, surge á preocupação de como atendê-la e promover a recuperação e a proteção ambiental sem prejudicar a viabilidade econômica da propriedade e, consequentemente, das famílias que dependem desta atividade para sua manutenção.

Desse modo, objetivou-se analisar a situação de três propriedades rurais, com características distintas (pequena, média e grande propriedade rural), visando á adequação 
ambiental, comparando a aplicabilidade da legislação antiga (Lei Federal $\mathrm{n}^{\mathbf{0}}$ 4.771/1965) com a atual legislação (Lei Federal $n^{\circ}$ 12.651/2012), observando os impactos oriundos dessa alteração sobre a ocupação das propriedades e também uma avaliação das áreas potenciais a serem utilizadas para composição da Reserva Legal.

\section{MATERIAL E MÉTODOS}

Para a realização do presente estudo, foram selecionadas três propriedades na região de Poço Fundo, sul do estado de Minas Gerais: uma pequena propriedade, uma média propriedade e uma grande propriedade, que representam as propriedades existentes na região.

A Propriedade 1, definida como de pequeno porte, está localizada no município de Poço Fundo, situada a 965 m de altitude, determinada pelas coordenadas geográficas $21^{\circ} 44^{\prime} 02^{\prime \prime}$ de Latitude Sul e 46 $01^{\prime} 27,04$ ' de Longitude Oeste. A área da propriedade é de 25,3179 hectares, configurando, segundo classificação do INCRA (1980), em menos de um Módulo Fiscal e possui como principal atividade a cafeicultura e a criação de gado em sistema extensivo de pastagens, ambas as atividades praticadas de modo familiar.

A Propriedade 2, definida como de médio porte está localizada no Município de Silvianópolis (MG), nas coordenadas $22^{\circ} 01^{\prime} 15,45^{\prime}$ de latitude Sul e $45^{\circ} 45^{\prime} 12,13^{\prime}$ longitude oeste, a uma altitude média de $840 \mathrm{~m}$. A área da propriedade é de 194,1829 ha, configurando, segundo classificação do INCRA (1980), em 6,47 módulos fiscais e possui como principal atividade a criação de gado em sistema extensivo de pastagens. Também apresenta como atividade complementar a cafeicultura.

A Propriedade 3, definida como de grande porte, está localizada no município de Campos Gerais (MG), apresentando as coordenadas geográficas $21^{\circ} 15^{\prime} 59,69^{\prime \prime} \mathrm{S}$ e 4549'55,44”'O, a uma altitude média de $805 \mathrm{~m}$. A área da propriedade é de 271,6177 ha, configurando, pela classificação do INCRA(1980), em 10,44 módulos fiscais. A principal atividade da propriedade é a criação de gado em pastagens, que ocupam 221,7937 ha. Há também pequenas áreas com cana-de-açúcar e eucalipto.

Inicialmente foi realizada uma apuração da legislação florestal aplicável, tanto a atual - Lei federal $\mathrm{n}^{\circ}$ 12.651, de 25 de maio de 2012 (BRASIL, 2012a), com alterações dadas pela Lei federal $n^{\circ} 12.727$, de 17 de outubro de 2012 (BRASIL, 2012b), quanto à legislação anterior (Lei federal $n^{\circ} 4.771$, de 15 de setembro de 1965 (BRASIL, 1965) e suas alterações.
Logo após, foi feito um levantamento de campo, juntando-se informações que permitiram definir o uso e ocupação do solo, posicionamento dos recursos hídricos disponíveis, localização e condições atuais das áreas de Preservação Permanente e Reserva Legal, em cada uma das propriedades estudadas.

Uma imagem de satélite de cada uma das propriedades foi obtida, através da utilização do programa Google Earth. Essa imagem serviu de orientação para a demarcação dos principais pontos de interesse, que foi feita, em cada uma das propriedades, através da utilização do aparelho receptor topográfico de dados do sistema GPS Promark100, de alta precisão $(5 \mathrm{~mm}+1 \mathrm{ppm})$, empregandose o Datum SIRGAS 2000. Para cada propriedade, foram demarcadas a área total, o uso e ocupação do solo, os recursos hídricos existentes e as áreas destinadas à Reserva Legal (RL) e Área de Preservação Permanente (APP).

Após esse levantamento, os dados obtidos foram processados, utilizando-se os softwares GNSS Solution e o programa AutoCAD, para elaboração dos mapas topográficos das propriedades. De posse do mapa topográfico de cada propriedade, foi realizada a análise, diagnóstico e adequação de cada propriedade à legislação ambiental vigente. Para efeito comparativo, foram compostas três tabelas das propriedades: a primeira, com a situação atual da propriedade, em relação aos aspectos de adequação à legislação ambiental, uso e ocupações atuais do solo. Uma segunda tabela foi projetada, com os aspectos de uso e ocupação do solo de cada propriedade adequados ao código florestal anterior (Lei $\mathrm{n}^{\circ}$ 4.771, de 1965, vigente até 2012). Por fim, uma última tabela foi elaborada, com adequações de uso e ocupação do solo das propriedades ao Novo Código Florestal (Lei $\mathrm{n}^{\circ} 12.651 \mathrm{com}$ alguns artigos alterados pela Lei $n^{\circ} 12.727$ ).

Foi feito um comparativo, utilizando-se as três tabelas de cada propriedade, entre a adequação Legislação atual e a anterior, através dos parâmetros determinados por cada uma dessas legislações no que se refere ao tamanho das áreas a serem destinadas para as APP's e RL e potenciais oportunidades para áreas não utilizadas.

\section{RESULTADOS E DISCUSSÃO}

\section{Uso e ocupação atual do solo das propriedades}

Após levantamento de dados em campo, relacionados ao uso e ocupação do solo e disponibilidade e localização dos recursos hídricos, foi elaborada a Tabela 1, que indica as áreas respectivas do uso e ocupação do solo das Propriedades 1,2 e 3 .

Tabela 1. Uso e ocupação atual do solo nas propriedades das cidades de Poço Fundo, Silvianópolis e Campos Gerais, respectivamente denominadas Propriedades 1,2 e 3 no ano de 2014.

\begin{tabular}{lcccccc}
\hline \multicolumn{1}{c}{ Uso/ocupação } & \multicolumn{2}{c}{ Propriedade 1 } & \multicolumn{2}{c}{ Propriedade 2 } & \multicolumn{2}{c}{ Propriedade 3 } \\
\hline & Área (ha) & \% da Área & Área (ha) & \% da Área & Área (ha) & \% da Área \\
\cline { 2 - 7 } Pastagens & 14,4477 & 57,06 & 151,8975 & 78,22 & 221,7937 & 81,69 \\
Mata Nativa & 0,7166 & 2,83 & 24,2848 & 12,51 & 40,5688 & 14,93 \\
Café & 8,4355 & 33,32 & 13,3733 & 6,89 & - & - \\
Edificações & 1,3601 & 5,37 & 4,6273 & 2,38 & - & 4,8700 \\
Eucalipto & 0,358 & 1,42 & - & - & 4,3852 & 1,78 \\
Cana de açúcar & - & - & - & $\mathbf{1 0 0}$ & $\mathbf{2 7 1 , 6 1 7 7}$ & $\mathbf{1 0 0}$ \\
\hline Total & $\mathbf{2 5 , 3 1 7 9}$ & $\mathbf{1 0 0}$ & $\mathbf{1 9 4 , 1 8 2 9}$ & $\mathbf{1 0 0}$ \\
\hline
\end{tabular}


A Propriedade 1 apresenta como principais recursos hídricos cinco córregos que, somados seus percursos, correspondem a uma extensão de 870,56 metros percorridos pelo interior e perímetro divisório do imóvel. Os córregos apresentam largura máxima, no período das cheias, inferior a 10 metros. Também apresenta duas nascentes de pequena vazão e um açude de pequeno porte.

Não há APP delimitada em nenhum ponto da propriedade. Margeando os córregos, há pouca vegetação, de modo irregular e descontínuo, com vastos pontos sem vegetação. A pastagem chega praticamente até a beira dos recursos hídricos. Em duas das nascentes pode ser observado um percentual maior de vegetação nativa, mas nenhum dos recursos hídricos da propriedade está cercado ou apresenta medidas de segurança contra incêndios, seguindo as indicações do Ministério do Meio Ambiente, em sua Instrução Normativa ${ }^{\circ} 5$ (MMA, 2009).

A propriedade não possui averbação de Reserva Legal (RL). Como mata nativa, possui 0,7166 ha, compostos por árvores nativas da região, mas essa fração de terras não está averbada.

A Propriedade 2 apresenta como principais recursos hídricos quatro córregos, todos com menos de $10 \mathrm{~m}$ de largura que, ao terem seus percursos somados, percorrem uma extensão de $4.545 \mathrm{~m}$, no interior e perímetro da propriedade, que também apresenta cinco açudes de pequeno porte, um açude de médio porte e três nascentes de pequena vazão.

Margeando os recursos hídricos, há uma vegetação composta por árvores nativas, mas não é contínua e nem está presente em todas as áreas delimitadas pelos recursos hídricos. Também não apresenta cercamento e nem proteção contra incêndios. Assim, não apresentam características que a configuram como efetivas APP's.

$\mathrm{O}$ total de matas existente na propriedade refere-se às essas áreas descontínuas que margeiam os recursos hídricos e a pequenos fragmentos espalhados pela propriedade, que também não apresenta Reserva Legal (RL) averbada.

A Propriedade 3 apresenta como principais recursos hídricos 17 açudes de pequeno e médio porte, 13 nascentes de pequena vazão e 13 pequenos córregos que, ao terem seus percursos somados, correspondem a uma extensão de $7.536,39 \mathrm{~m}$., percorridos no interior e perímetro divisório do imóvel. O total de matas na propriedade refere-se aos remanescentes de vegetação dentro da propriedade, que não possui Reserva Legal averbada. Alguns desses remanescentes localizam-se margeando os cursos d'água, mas de modo irregular e descontínuo, sem cercamento ou proteção contra incêndio, não configurando APP's efetivas.

\section{Adequações das propriedades à Lei no $4.771 / 1965$}

Como os cursos d'água existentes nas propriedades apresentam largura máxima inferior a 10 metros, a Lei $\mathrm{n}^{\mathbf{0}}$ 4.771 (BRASIL, 1965), em seu segundo artigo, indica que devem ser consideradas como área de Preservação Permanente (APP) as florestas e demais formas de vegetação situadas de 30 metros do nível mais elevado do curso d’água. Para as nascentes, a mesma legislação indica, também no mesmo artigo, que devem ser considerados como APP, as florestas e demais formas de vegetação localizadas num raio de 50 metros de largura. No caso de açudes, foi considerada a Lei $\mathrm{n}^{\circ} 14.309 / 2002$ (MINAS GERAIS, 2002), que dispõe sobre as políticas de florestal e de proteção à biodiversidade em Minas Gerais. Assim, essa lei indica em seu $10^{\circ}$ artigo, que ao redor de reservatório de água naturais ou artificiais, devem ser mantidos como APP uma faixa marginal com largura mínima de $30 \mathrm{~m}$.

Desse modo, na Propriedade 1, a Área de Preservação Permanente (APP) deveria ser, somando-se os três cursos d'água existentes e as duas nascentes, de 5,0843 ha. Como já existe uma vegetação ao redor de alguns trechos de córregos e nascentes, no total de 0,7166 ha, para a recomposição das APP's é necessário um acréscimo de 4,3677 ha, que seriam retirados das áreas de pastagem, eucalipto e através da remoção de algumas benfeitorias, por estarem localizadas dentro das áreas de APP's.

Para a Propriedade 2, somando-se os cursos d'água, açudes e nascentes existentes, a área de APP deveria ser de 23,1976 ha. Como 13,6768 ha da mata nativa estão em áreas de APP, será necessária recomposição de 9,5208 ha, retirados da área de pastagem, que está próxima aos cursos d'água, para que o total seja atingido.

No caso da Propriedade 3, usando os mesmos critérios, a APP deveria ser de 46,21866 ha. Como 15,16376 ha compõe-se da área de mata nativa, é necessária a recomposição de 31,0549 ha, retirados das áreas de pastagem, cana-de-açúcar e eucalipto, por estarem nas áreas de preservação obrigatórias.

Em relação à Reserva Legal (RL), essa mesma lei determina, em seu $16^{\circ}$ artigo, que $20 \%$ da propriedade sejam destinados á área de Reserva Legal. Para Propriedade 1 seria o equivalente a 5,06358 ha, que seriam totalmente retirados das áreas de pastagem, para o cumprimento da legislação. Para a Propriedade 2, o total necessário para compor a RL é de 38,83658 ha. Deste modo seriam utilizados 10,6080 ha do fragmento de mata fora do perímetro das APP's, associados a 28,2285 ha retirados da área de pastagem. Para a Propriedade 3, a área a ser destinada à RL é de 54,32354 ha. Assim, seriam utilizados 25,4050 ha de fragmentos de mata nativa localizada fora do perímetro das APP's, somados a 28,9185 ha a serem retirados da área de pastagem.

A Tabela 2 apresenta as novas configurações de uso e ocupação do solo das Propriedades 1, 2 e 3, após as adequações à Lei $n^{\circ}$ 4.771/1965 e suas alterações posteriores.

Em relação à Propriedade 1, para o cumprimento da lei $n^{o}$ 4.771/65, há uma significativa redução da área de pastagem, que passaria de 14,4477 ha (Tabela 1) para 5,2626 ha (Tabela 2), ou seja, uma diminuição de 9,1851 ha, ou $63,57 \%$. Verifica-se também que a área de eucalipto sofreria uma redução de $31,8 \%$ e a área constituída por edificações e benfeitorias da propriedade seria reduzida em 9,72\%. Assim, para o cumprimento dessa legislação, cerca de $40 \%$ da propriedade deveria ser convertida em áreas protegidas, nas quais atividade agropecuária não poderia ser efetuada (Tabelas 1 e 2).

No caso da Propriedade 2, em atendimento a essa legislação, a área de pastagem sofreria uma redução de $24,85 \%$, ou 37,75 ha, que seriam utilizados para a recomposição da RL e da APP (Tabela 2). Para escolha da localização da área de Reserva Legal a ser recomposta considerou-se a possibilidade da formação corredores ecológicos, áreas com declividades mais altas, ampliação da proteção de nascentes e o menor impacto na atividade econômica do imóvel. Desse modo, as demais culturas agrícolas da propriedade não sofreram redução em suas áreas. Cerca de $32 \%$ da propriedade seria convertida em áreas 
protegidas, nas quais não seria possível a prática de atividades agropecuárias (Tabelas 1 e 2).

$\mathrm{Na}$ Propriedade 3, a área de pastagem seria reduzida em 57,88 ha ou $26 \%$, a serem utilizados para recomposição da APP e RL. As áreas de cana-de-açúcar e eucalipto também sofreriam reduções $(38 \%$ e $8,55 \%)$, por estarem em áreas de recomposição de APP (Tabelas 1 e 2). Os critérios escolhidos para a escolha das áreas de recomposição foram os mesmos estabelecidos para a propriedade 2. Desse modo, cerca de $37 \%$ da propriedade seria destinada às áreas protegidas, nas quais não seria possível a produção agropecuária.

Tabela 2. Uso e ocupação do solo nas propriedades de Poço Fundo, Silvianópolis e Campos Gerais, respectivamente denominadas Propriedades 1,2 e 3 no ano de 2014, em adequação à Lei no 4.771/1965.

\begin{tabular}{lcccccc}
\hline \multicolumn{1}{c}{ Uso/ocupação } & \multicolumn{2}{c}{ Propriedade 1 } & \multicolumn{2}{c}{ Propriedade 2 } & \multicolumn{2}{c}{ Propriedade 3 } \\
\hline & Área (ha) & \% da Área & Área (ha) & \% da Área & Área (ha) & \% da Área \\
\cline { 2 - 7 } Pastagens & 5,2626 & 20,79 & 114,1482 & 58,78 & 163,9127 & 60,35 \\
Café & 8,4355 & 33,32 & 13,3733 & 6,89 & - & - \\
Edificações & 1,2279 & 4,85 & 4,6273 & 2,38 & - & 4,4539 \\
Eucalipto & 0,2441 & 0,96 & - & - & 2,7089 & 0,99 \\
Cana de açúcar & - & - & - & 7,04 & 15,1637 & 5,58 \\
APP em mata nativa & 0,7166 & 2,83 & 13,6768 & 5,47 & 25,4050 & 9,35 \\
RL em mata nativa & - & - & 10,608 & 4,9 & 31,055 & 11,43 \\
APP a ser recomposta & 4,3677 & 17,25 & 9,5208 & 14,55 & 28,9185 & 10,65 \\
RL a ser recomposta & 5,0635 & 20,00 & 28,2285 & $\mathbf{1 0 0}$ & $\mathbf{2 7 1 , 6 1 7 7}$ & $\mathbf{1 0 0}$ \\
\hline Total & $\mathbf{2 5 , 3 1 7 9}$ & $\mathbf{1 0 0}$ & $\mathbf{1 9 4 , 1 8 2 9}$ & $\mathbf{1 0 0}$ \\
\hline
\end{tabular}

Adequações das propriedades à Lei $\mathbf{n}^{\circ}$ 12.651/2012, com alterações dadas pela Lei $^{\circ} \mathbf{1 2 . 7 2 7 / 2 0 1 2}$

Em relação às áreas de Preservação Permanente, a Lei $\mathrm{n}^{\circ} 12.651$ (BRASIL, 2012a) indica situação semelhante à da Lei $n^{\circ} 4.771$ (BRASIL, 1965), ou seja, devem ser consideradas como APP as faixas marginais com largura mínima de 30 metros, para os cursos d'água que apresentem largura inferior a 10 metros. No entanto, pela nova legislação, é permitida, em algumas situações, a continuidade das atividades agrossilvipastoris em áreas rurais consolidadas em 22 de julho de 2008, que é o caso da propriedade. Assim, a nova legislação determina que, para propriedades com menos de um Módulo Fiscal (MF), é obrigatória a recomposição da faixa marginal em 5 metros, independente da largura do rio. Para propriedades entre 1 e $2 \mathrm{MF}$, a recomposição das faixas marginais deve ser de 8 metros e para propriedades entre 2 e 4 MF, a recomposição deverá ser de 15 metros, também independente da largura do rio. E, no caso de nascentes, quando se localizarem em áreas rurais consolidadas, a recomposição deverá ocorrer num raio de 15 metros, independente do tamanho da propriedade. No entorno de reservatórios artificiais de água que não decorram de barramento ou represamento de cursos d'água naturais, não é necessária a criação de APP's, que também é dispensada no caso de acumulações naturais ou artificiais de água com superfície inferior a 1 ha (BRASIL, 2012a).

Assim, para a Propriedade 1, como possui menos de um MF, a recomposição de faixas marginais deve ser de 5 metros e o somatório de todas as APP's a serem recompostas ocuparia uma área de 0,4909 ha, uma vez que duas das três nascentes apresentam vegetação dentro da faixa necessária.

No caso da Propriedade 2, como apresenta mais de 4 MF, a recomposição das faixas marginais ao redor dos curso d'água será de 30 metros. Observando os demais critérios previstos na lei, a propriedade deverá recompor 6,6331 ha de APP que, ao serem somados com as áreas de mata localizadas nas áreas de APP resultarão no número, em ha, necessários para a adequação correta.
No caso da Propriedade 3, será necessária a recomposição de 26,4749 ha em áreas de APP, que também somados aos há com mata nativa em áreas de APP, promovem a adequação da propriedade.

Já no que diz respeito à Reserva Legal, a lei $\mathrm{n}^{\circ}$ 12.651 (BRASIL, 2012a) também apresenta as mesmas indicações que a Lei $n^{\circ} 4.771$ (BRASIL, 1965), ou seja, todo imóvel rural no Brasil, exceto os localizados dentro da Amazônia Legal devem destinar $20 \%$ da sua área para a composição da Reserva Legal. Entretanto, a legislação atual indica, em seu $67^{\circ}$ artigo, que, para propriedades com até 4 Módulos Fiscais, com percentual de vegetação remanescente, em 22 de julho de 2008, inferior ao previsto na lei, pode ser constituída como Reserva Legal (RL) a área com vegetação nativa existente nessa dada, sendo impedida a conversão de novas áreas para uso alternativo do solo. Outra alteração importante da nova legislação, em seu $15^{\circ}$ artigo, diz respeito ao somatório das áreas de APP para recomposição da RL, que é permitido em qualquer situação, desde que esse benefício na implique na conversão de outras áreas para uso alternativo do solo, a área a ser utilizada no cômputo esteja conservada ou em processo de recuperação, mediante comprovação do proprietário junto à órgãos integrantes do Sisnama e o proprietário tenha realizado ou requerido sua inscrição no CAR - Cadastro Ambiental Rural (BRASIL, 2012a).

Assim, no caso da Propriedade 1, como possui menos de $1 \mathrm{MF}$, será constituída como RL o que existia em 22 de julho de 2008, ou seja, 0,7166 ha de vegetação nativa, sendo impedida a conversão de novas áreas para uso alternativo do solo. Em relação à Propriedade 2, Reserva legal será composta pela soma da área de Matas, APP a ser recomposta e área RL a ser recomposta, que é de 6,6361 ha. A Reserva Legal, na Propriedade 3, será composta pela soma da área de vegetação nativa (40.56.88 ha), mais parte da área destinada a recomposição da APP (13.75.47 ha),totalizando 54.32.35 ha como RL.

A Tabela 3 apresenta as novas configurações de uso e ocupação do solo das três propriedades após as adequações à Lei no 12.651/2012. 
Tabela 3. Uso e ocupação do solo nas propriedades de Poço Fundo, Silvianópolis e Campos Gerais, respectivamente denominadas Propriedades 1,2 e 3 no ano de 2014, em adequação à Lei no 12.651/2012.

\begin{tabular}{lcccccc}
\hline \multicolumn{1}{c}{ Uso/ocupação } & \multicolumn{2}{c}{ Propriedade 1 } & \multicolumn{2}{c}{ Propriedade 2 } & \multicolumn{2}{c}{ Propriedade 3 } \\
\hline & Área (ha) & \% da Área & Área (ha) & \% da Área & Área (ha) & \% da Área \\
\cline { 2 - 7 } Pastagens & 13,9568 & 55,13 & 137,3458 & 70,74 & 197,4112 & 72,68 \\
Café & 8,4355 & 33,32 & 13,3733 & 6,89 & - & - \\
Edificações & 1,3601 & 5,37 & 4,6273 & 2,38 & - & 4,4539 \\
Eucalipto & 0,3580 & 1,41 & - & - & 2,7089 & 0,99 \\
Cana de açúcar & - & - & - & 12,51 & 40,5688 & 14,94 \\
Mata nativa & 0,7166 & 2,83 & 24,2848 & 4,07 & 26,4749 & 9,75 \\
APP a ser recomposta & 0,4909 & 1,94 & 7,9156 & 3,41 & - & - \\
RL a ser recomposta & - & 0 & 6,6361 & $\mathbf{1 0 0}$ & $\mathbf{2 7 1 , 6 1 7 7}$ & $\mathbf{1 0 0}$ \\
\hline Total & $\mathbf{2 5 , 3 1 7 9}$ & $\mathbf{1 0 0}$ & $\mathbf{1 9 4 , 1 8 2 9}$ & & &
\end{tabular}

Para atendimento a essa legislação, no caso da Propriedade 1 , a área a ser recomposta seria retirada da área de pastagem, que margeia os cursos d'água. No total, a área de pastagem sofreria uma redução de apenas 3,4\% (Tabelas 1 e 3).

Em relação à adequação da Propriedade 2, é necessária uma redução de apenas $9,49 \%$ na área de pastagem, uma vez que 14,5517 ha desta área deverão ser convertidas em APP e RL (Tabelas 1 e 3)

No caso da Propriedade 3, para atendimento a essa legislação, é necessária a conversão de 24,3825 ha da área de pastagem, com redução de $11 \%$ na mesma. Também seriam necessárias reduções nas áreas de cana-de-açúcar e eucalipto (38\% e 8,55\%), por estarem em áreas de recomposição de APP (Tabelas 1 e 3).

Ao se fazer um comparativo entre as legislações, utilizando-se os dados constantes nas Tabelas 1, 2 e 3, o Novo Código Florestal - Lei No 12.651 (BRASIL, 2012a) apresentou, pelo menos em curto prazo, condições melhores de desenvolvimento econômico que o código anterior (BRASIL, 1965) nas três propriedades analisadas, uma vez que, com o atendimento à nova legislação, as propriedades apresentam reduções em áreas produtivas bem inferiores ao necessário para o atendimento à Lei $n^{\circ} 4.771 / 1965$. Na Propriedade 1, tal fato é bastante considerável, uma vez que, pela legislação anterior, a pastagem sofreria uma redução de mais de $60 \%$ e pela nova legislação, essa redução será de apenas $3,4 \%$, sem que ocorra a necessidade da conversão de benfeitorias ou outras áreas agrícolas para a recomposição das áreas protegidas. Assim, por ser pequena propriedade, a adequação à legislação antiga poderia dificultar a manutenção econômica da propriedade, que ainda fica com uma considerável área de pastagem. Mas os benefícios econômicos podem ser observados nas três áreas estudadas. As propriedades maiores se beneficiaram, principalmente, pela redução da área de APP em nascente para áreas rurais consolidadas e pela possibilidade do somatório das áreas de APP para a composição da RL, em qualquer porcentagem ou tamanho da propriedade, desde que sejam respeitados alguns requisitos previstos na lei. Giunti et al. (2014) ao adequarem e compararem uma pequena propriedade em relação às duas legislações ambientais tiveram resultados semelhantes. Balestrin, Balbinot e Valerius (2013), ao compararem as exigências dos dois códigos florestais em pequenas propriedades rurais no Rio Grande do Sul, observaram que, com as alterações no código atual, o número de propriedades irregulares foi reduzido, com elevação das propriedades legalizadas através da nova legislação.
No que tange à questão ambiental, o Novo Código Florestal pode comprometer a conservação da biodiversidade e a qualidade de água, devido à redução nas áreas de APP e $\mathrm{RL}$ a serem mantidas nas propriedades agrícolas. Crivelenti et al. (2014) obtiveram conclusões semelhantes ao estudarem a adequação de uma propriedade agrícola no interior do estado de São Paulo. De acordo com Santos Filho et al. (2015), o atual Código Florestal apresentou, para alguns temas, retrocessos no que se refere à proteção ambiental, principalmente oriundos da grande influência da bancada ruralista no Congresso Nacional em sua elaboração, ao mesmo tempo em que importantes avanços também ocorreram. Ao considerar, em propriedades com até $4 \mathrm{MF}$ e em áreas rurais consolidadas até 22 de julho de 2008, como RL o percentual de vegetação nativa existente nessa data, o novo Código Florestal pode reduzi significativamente a porcentagem dessas áreas dentro das propriedades rurais, influenciando a conservação da biodiversidade, a restauração de processos ecológicos e a acolhida e proteção da fauna e flora nativa. E, ao permitir o somatório das áreas de preservação permanente para a composição da reserva legal em qualquer situação, o Novo Código coloca essas duas áreas como equivalentes. Nesse sentido Metzger (2010) indica que não podem ser consideradas análogas, quando na verdade são distintas biologicamente e se complementam, pois cada uma dela protege espécies diferentes. Tambosi et al. (2015) apontam que as alterações promovidas por esse novo código, principalmente no que referem-se às áreas de vegetação nativa a serem conservadas e/ou preservadas em propriedades rurais podem remodelar as funções eco hidrológicas exercidas por essas áreas, possibilitando uma redução na quantidade e qualidade da água compatíveis com as demandas futuras. Tundisi e Tundisi (2010) observam que a redução da necessidade de regeneração de áreas ripárias e naturalmente alagadas pode comprometer a regulação dos ciclos hidrológicos e biogeoquímicos, inviabilizando a agricultura em um curto prazo.

Sparovek et al. (2011) ainda apontam que , mesmo sendo interessante, economicamente, a redução do percentual de RL em propriedades com menos de $4 \mathrm{MF}$, tal fato, dependente da situação da propriedade em uma data específica, no caso 22 de julho de 2008, pode dificultar a fiscalização, resultando em áreas sem proteção temporária, que podem ser desmatadas até que se consiga o monitoramento e fiscalização adequada das mesmas.

Nery et al. (2013), ao analisarem as áreas de preservação permanente em topo de morro no norte de Minas Gerais, em uma sub-bacia hidrográfica, observaram uma 
redução de $13,05 \%$ nessas áreas, através das modificações ocorridas no novo Código Florestal, o que pode comprometer a preservação ambiental da região. Soares Filho et al. (2014) concluíram que o código florestal atual pode reduzir em até $58 \%$ o total de áreas desmatadas no Brasil que deveriam ser restauradas, o equivalente a 29 milhões de ha. Um estudo realizado pela ONG TNC - The Nature Conservancy (G1, 2014) apontou que a implementação do novo código promoveu, em um ano, dependendo da região, perdas entre $15 \%$ e $40 \%$ das áreas previstas para conservação e preservação obrigatórias. Ao mesmo tempo, o estudo apontou que, pelas facilidades práticas na aplicação desse código, pode ser que ocorra uma preservação mais efetiva. Essa facilidade e maior flexibilidade de aplicação do novo código foram apontadas como facilitadoras ao cumprimento da legislação pelos proprietários das três propriedades analisadas.

\section{CONCLUSÕES}

O Novo Código Florestal (Lei ${ }^{\circ} 12$. 651/2012), ao ser comparado com a Lei $\mathrm{n}^{\circ} 4771 / 1965$, mostrou-se mais benéfico às três propriedades, do ponto de vista econômico. Como nenhuma das propriedades possui ainda a Reserva Legal averbada e nem Área de Preservação Permanente regulamentada, a área destinada para a regularização dessas figuras jurídicas pela nova legislação ambiental mostrou-se inferior à exigida pela legislação anterior, o que pode resultar na continuidade da exploração agrícola em algumas áreas que anteriormente deveriam ser consideradas de preservação ou conservação, com utilização extremamente restrita. A pequena propriedade ainda beneficiou-se do fato da legislação permitir a continuidade das atividades agrícolas consolidadas até 22 de julho de 2008, em áreas de APP e RL, considerando como RL o remanescente de vegetação que existia nessa data. Assim, através da nova legislação um grande número de propriedades irregulares pode conseguir resolver sua situação legal. Do ponto de vista ambiental, pode reduzir a quantidade e qualidade dos recursos hídricos e da biodiversidade como um todo, por diminuir as Áreas de Preservação Permanente e de Reserva Legal, com consequências a médio e longo prazo.

\section{REFERÊNCIAS}

ALBERTI, M. Maintaining ecological integrity and sustaining ecosystem function in urban areas. Current Opinion in Environmental Sustainability, v. 2, n. 3, p. 178184, 2010.

ATTANASIO, C. M.; RODRIGUES, R. R.; GANDOLFI, S.; NAVE, A. G. Adequação ambiental de propriedades rurais. Recuperação de áreas degradadas. Restauração de matas ciliares. Piracicaba: Universidade de São Paulo/Escola Superior de Agricultura Luiz de Queiroz, 2006. 63 p.

BALESTRIN, D.; BALBINOT, R.; VALERIUS, J. Código florestal e aplicações práticas na pequena propriedade rural. Revista Eletrônica em Gestão, Educação e Tecnologia Ambiental, v. 14, n. 14, p. 2885-2892, 2013.

BORGES, L. A. C.; REZENDE, J. L. P.; PEREIRA, J. A. A.; COELHO JÚNIOR, L. M.; BARROS, D. A. Áreas de preservação permanente na legislação ambiental brasileira. Ciência Rural, v. 41, n. 7, p. 1202-1210, 2011.

BRASIL. Lei ${ }^{\circ}$ 4.771, de 15 de setembro de 1965. Institui o novo Código Florestal. Brasília: Presidência da República, 1965.

BRASIL. Lei $\mathrm{n}^{\circ} 12.651$, de 25 de maio de 2012. Dispõe sobre a proteção da vegetação nativa; altera as Leis $\mathrm{n}^{\mathrm{os}}$ 6.938, de 31 de agosto de 1981, 9.393, de 19 de dezembro de 1996, e 11.428, de 22 de dezembro de 2006; revoga as Leis $n^{\text {os }} 4.771$, de 15 de setembro de 1965, e 7.754, de 14 de abril de 1989, e a Medida Provisória n ${ }^{\circ}$ 2.166-7, de 24 de agosto de 2001 e dá outras previdências. Brasília: Presidência da República, 2012a.

BRASIL. Lei $\mathrm{n}^{\mathrm{o}} 12.727$, de 17 de outubro de 2012. Altera a Lei $\mathrm{n}^{\circ} 12.651$, de 25 de maio de 2012, que dispõe sobre a proteção da vegetação nativa; altera as Leis $n^{\text {os }} 6938$, de 31 de agosto de 1981, 9.393, de 19 de dezembro de 1996, e 11.428, de 22 de dezembro de 2006; revoga as Leis $\mathrm{n}^{\text {os }} 4.771$, de 15 de setembro de 1965 , e 7.754 , de 14 de abril de 1989, e a Medida Provisória $n^{\circ}$ 2.166-7, de 24 de agosto de 2001, o item 22 do inciso II do art. 167 da Lei $n^{\circ}$ 6.015, de 31 de dezembro de 1973 e o $\S 2^{\circ}$ do art. $4^{\circ}$ da Lei ${ }^{\circ} 12.651$, de 25 de maio de 2012. Brasília: Presidência da República, 2012b.

CASTAGNARA, D. D.; UHLEIN, A.; FEIDEN, A.; WAMMES, E. V. S.; PERINI, J.; STERN, E.; ZANELATO, F. T.; VERONA, D. A.; ULIANA, M. R. B.; ZONIN, W. J.; SILVA, N. L. S. Importância ambiental das áreas de reserva legal e sua quantificação na microbacia hidrográfica da Sanga Mineira do município de Mercedes, PR. Revista Brasileira de Agroecologia, v. 2, n. 2, p. 1420-1423, 2007.

CRIVILENTI, R. C.; BUENO, C. R. P.; MIJONE, A. P.; DAMASCENO, G. F. Implicações do Novo Código Florestal no planejamento do uso do solo da fazenda de ensino, pesquisa e extensão. Floresta, v. 44, n. 2, p. 271-278, 2014.

G1. Novo Código Florestal fez país perder até $40 \%$ de áreas protegidas, diz ONG. G1 Natureza. Disponível em: <g1.globo.com>. Acesso em: 03 mar. 2016.

GIUNTI, O. D.; SÁ, E. B. R.; OLIVEIRA, T. C.; SILVA, A. V. Análise e diagnóstico ambiental: adequações ao Novo Código Florestal - um estudo de caso. Revista Agrogeoambiental, edição especial n. 2, p. 33-39, 2014.

INSTITUTO NACIONAL DE COLONIZAÇÃO E REFORMA AGRÁRIA (INCRA). Instrução especial nº 20, de 28 de maio de 1980. Estabelece o Módulo Fiscal de cada Município, previsto no Decreto $n^{\circ} 84.685$, de 06 de maio de 1980. Brasília: INCRA, 1980.

METZGER, J. P. O Código Florestal tem base científica? Natureza e Conservação, v. 8, n. 1, p. 1-5, 2010.

MINAS GERAIS. Lei n 14.309, de 19 de junho de 2002. Dispõe sobre as Políticas Florestais e de proteção à biodiversidade no Estado. Belo Horizonte: Diário Executivo de Minas Gerais, 2002. 
MINISTÉRIO DO MEIO AMBIENTE (MMA). Instrução Normativa $n^{\circ} 5$, de 08 de setembro de 2009. Dispõe sobre os procedimentos metodológicos para a restauração e recuperação das Áreas de Preservação Permanentes e da Reserva Legal, instituídos pela Lei $\mathrm{n}^{\mathrm{o}} 4.771$, de 15 de setembro de 1965. Brasília: Ministério do Meio Ambiente, 2009.

NERY, C. V. M.; BRAGA, F. L. MOREIRA, A. A.; FERNANDES, F. H. S. Aplicações do Novo Código Florestal na avaliação das áreas de preservação permanente em topo de morro na sub-bacia do Rio Canoas, no município de Montes Claros/MG. Revista Brasileira de Geografia Física, v. 6, n. 6, p. 1673-1688, 2013.

RIBEIRO, G. V. B. A origem histórica do conceito de área de preservação permanente no Brasil. Revista Thema, v. 8, n. 1, p. 01-13, 2011.

TAGLiAlEGNA, G. H. F. Reforma do Código Florestal: busca do equilíbrio entre a agricultura sustentável e a preservação do meio ambiente. In: MENEGUIN, F. B. (Org.). Agenda Legislativa para o Desenvolvimento Nacional. 596 ed. Brasília: Senado Federal, 2011, v. 1, p. 59-72.

RIBEIRO, M.C.; METZGER, J. P.; MARTENSEN, A. C.; PONZONI, J. F.; HIROTA, M. M. The Brazilian Atlantic Forest: how much is left, and how is the remaining forest disturbed? Implications for conservation. Biological Conservation, v. 142, p. 1141-1153, 2009.

SANTOS FILHO, A. O. A evolução do Código Florestal brasileiro. Cadernos de Graduação, v. 2, n. 3, p. 271-290, 2015.

SEOANE, C. E. S. Recuperação de áreas degradadas como instrumento para conservação das florestas nativas. In: SEMINÁRIO CATARINENSE DE ESTUDOS FLORESTAIS, 1, 2007, Xanxerê. Anais... Xanxerê: UNOESC, Centro Acadêmico de Engenharia Florestal, 2007.

SEOANE, C. E. S.; DIAZ, V. S.; SANTOS, T. L.; FROUFE, L. C. M. Corredores ecológicos como ferramenta para a desfragmentação de florestas tropicais. Pesquisa Florestal Brasileira, v. 30, n. 63, p. 207-2016, 2010.

SOARES-FILHO, B.; RAJÃO, R.; MACEDO, M.; CARNEIRO, A.; COSTA, W.; COE, M.; RODRIGUES, H.; ALENCAR, A. Cracking Brazil's Forest Code. Science, v. 344, iss. 6182, p. 363-364, 2014.

SPAROVECK, G.; BARRETTO, A.; KLUG, I.; PAPP, L.; LINO, J. A revisão do Código Florestal brasileiro. Novos Estudos, n. 89, p. 111-135, 2011.

TAMBOSI, L. R.; VIDAL, M. M.; FERRAZ, S.F.B.; METZGER, J. P. Funções eco hidrológicas das florestas nativas e o Código Florestal. Estudos Avançados, v. 29, n. 84, p. $151-162,2015$.
TUNDISI, J. G.; TUNDISI, T. M. Impactos potenciais das alterações do Código Florestal nos recursos hídricos. Biota Neotropica, v. 10, n. 4, p.67-75, 2010.

ZAKAIA, M. J.; PINTO, L. F. G. Guia para aplicação da nova lei em propriedades rurais. Piracicaba: Imaflora, 2013. $32 \mathrm{p}$. 